\title{
Exploring the Experiences of Upper Elementary School Children Who are Intrinsically Motivated to Seek Information
}

\author{
Sherry R. Crow, M.L.S., Ph.D. \\ Assistant Professor of School Library Science/Educational Media \\ University of Nebraska Kearney \\ USA
}

\begin{abstract}
This paper describes a naturalistic research study based on the following question, "what are the experiences in the lives of upper elementary school children that foster an intrinsic motivation to seek information?" Participants were ten-year-olds selected using a specially-created survey. Analysis, based on data collected through interviews and drawings, indicates that students came from various family and socioeconomic backgrounds, exhibited an affinity for play, and tended to be creative and non-competitive. A point-of-passion experience occurred in the lives of all of the informants, as well as the presence of "anchor" relationships. Students specified components of intrinsically motivating information seeking episodes.
\end{abstract}

Intrinsic motivation, youth information seeking, school libraries

\section{Introduction}

There is a tension for library media specialists in this age of testing and the No Child Left Behind Act (2001). Library media specialists want to help their schools meet educational requirements for learning, yet they also want to provide environments for students that foster a love of information seeking that will endure into students' adult lives. Current standards and testing procedures in American schools often skew attention away from learning in the broad sense and reduce education to what is being tested (Sheldon \& Biddle, 1998). How do these educational practices affect the intrinsic motivation of students? How do they affect the potential for cultivating lifelong learning in students? Are the goals of our school system and the resultant teaching strategies "sabotag[ing] a key goal of education-creating a flexible population of life-long learners who can adjust to the changing needs of society and the workplace" (p. 164)? Is the educational system actually working against the goals of fostering intrinsic motivation to seek information, and therefore lifelong learning, in students?

Of course school success and student motivation are affected by factors other than the school environment. The home environment, especially parental support for learning, is also key. What experiences outside of school might be contributing to students' eagerness to learn? 


\section{Background}

Whatever the reason, most children experience a decline in academic intrinsic motivation over their years in school. However, research has shown that some children maintain their excitement and a disposition toward intrinsic motivation for learning throughout their elementary years (Lepper, Corpus, \& Iyenger, 2005). Within a school context, looking at the "starting block," the initial moment and place where students begin seeking information on a particular topic, the point at which they begin to manifest the desire to "know something more," does not tell the story of why some students have a disposition toward intrinsic motivation to seek information and others do not. These individual starting block experiences are virtually invisible, mostly based on what Taylor termed "a cognitive level of visceral need" (1968). What will lead to a discovery, then, of what is different about these children who maintain the disposition toward intrinsic motivation to seek information?

\section{Purpose and Research Question}

The research for this study, undertaken during the fall of 2008, sought to understand the experiences of children in order to inform school library media specialists' practice in fostering the development of intrinsic motivation for information seeking in young patrons. Research was conducted using an inductive naturalistic approach in order to address the following question, "what are the experiences in the lives of upper elementary school children that foster an intrinsic motivation to seek information?"

\section{Literature Review}

The research question contains strands of thought that encompass the issues of information seeking, intrinsic motivation, and naturalistic research, all within the context of the lives of children.

\section{Information Seeking and Youth}

The review of the literature about information seeking and youth includes early nonempirical articles on children's use of new technologies (e.g., Clyde \& Kirk, 1989; Aversa, 1985; Kuhlthau \& Sherman, 1990; Mancall \& Desking, 1984; Montogomery, 1987; Tenopir, 1986; Ward-Callaghan, 1987), system-oriented studies (e.g., Callison, Daniels, Estell, \& Gunderson, 1986; Craver, 1985; Edmonton Public Schools, 1983; Wozny, 1982), useroriented studies (e.g., Barlow, Karnes, \& Marchionini, 1987; Bilal, 2000, 2001, 2003; Borgman, Chignell, \& Valdez, 1989; Borgman, Krieger, Gallagher, \& Bower, 1990; Kuhlthau, 2004; Large, Beheshti, \& Rahman, 2002, Liebscher \& Marchionini, 1988; Marchionini \& Teague, 1987), and information seeking in context (e.g., Agosto \& HughesHassell, 2006a, 2006b; Farmer, 2007; Gross, 1995; Hirsh, 1999; Oliver \& Oliver, 1997; Poston-Anderson \& Edwards, 1993; Schacter, Chung, \& Dorr, 1998; Shenton, 2004; Todd, 1999a, 1999b). 


\section{Intrinsic Motivation and Youth}

The review of the literature about intrinsic motivation and youth includes an overview of mechanistic (e.g., Freud, 1914, 1915; Hull, 1843) and organismic (e.g., Vroom, 1964; Berlyne, 1960; Csikzentmilalyi, 1975; Deci \& Ryan, 1985) motivational theory, and an examination of the research on intrinsic motivation based on interest in the task (e.g., Csikszentmihaly, 1975, 1990; Hidi \& Baird, 1986; Koch, 1956, 1961; Krapp \& Fink, 1992), as well as based on the satisfaction of the person (e.g., Deci \& Ryan, 1985; Harter, 1980, 1981; Lepper, Corpus, \& Iyengar, 2005; White, 1959; Murray, 1938). Literature about motivation and youth in LIS features studies about student motivation/frustration while using technology (e.g., Borgman, Hirsh, Walter, \& Gallagher, 1995; Broch, 2000; Solomon, 1993), the use of Accelerated Reader ${ }^{\mathrm{TM}}$ as a motivational tool (e.g., Everhart, 2005; Krashen, 2003; McLoyd, 1979; Robbins \& Thompson, 1991), the library media specialists' use of motivational strategies in instruction (Small, 1998, 1999), and the motivation of the student during the information searching process (Burdick, 1996; Kuhlthau, 2004).

\section{Theoretical and Conceptual Frameworks}

The theoretical framework for the study defined and conceptualized the social contexts that either foster or hinder the individual's intrinsic motivation to seek information. The Self-determination Theory (SDT; Deci \& Ryan, 1985), firmly rooted in the theory and research concerning intrinsic motivation and children, provided the basis for the theoretical framework. The factors that make SDT an appropriate theoretical framework for a study of experiences that foster intrinsic motivation are the epistemological, ontological, and axiological assumptions of the theory relative to the research question, its distinct treatment of the construct of intrinsic motivation, SDT's specific frameworks for examining social contexts and causality orientations that facilitate or undermine intrinsic motivation, and its compatibility with accepted principles and practices of human development and learning. Of particular importance to the current study is SDT's Cognitive Evaluation Theory, a subtheory which proposes that social conditions that produce a sense of autonomy and feelings of competence catalyze one's inherent tendency toward intrinsic motivation. Additionally, the subtheory posits that relatedness has also been found to be a significant factor (Ryan \& Deci, 2000).

The conceptual framework was composed of two information seeking models: the Taxonomy of Tasks (Bilal, 2002), and A Theoretical Model of Urban Teen Development (Agosto \& Hughes-Hassell, 2006a, 2006b). The Taxonomy of Tasks addresses the context, with reference to task definition, of the particular questions students ask. For the current research, it directed the collection and organization of questions being asked by the students under study. Its use helped in understanding the task definition of students' questions and the reasons behind their success or failure, as well as their preferences, in answering these questions. The current study also used A Theoretical Model of Urban Teen Development to classify and sort the topics of interest generated by the intrinsically-motivated students under study. The seven independent variables in the Agosto Hughes-Hassell model-the emotional self, the reflective self, the physical self, the creative self, the cognitive self, the sexual self, and the social self-are based on personal and cultural situations and settings. Use of the model illuminated the socio-cultural, as well as developmental, reasons behind the information seeking behaviors of the student participants. 


\section{Methodology}

Participants were selected from a pool of fifth graders from three diverse schools within a single community in Colorado Springs, CO. Initially, the children were chosen based on the results of a survey (The Information Seeking Self-Regulation Questionnaire [SRQ-IS]) especially developed (by the author with the aid of Dr. Ruth Small and the advice of Dr. Edward Deci and Dr. Richard Ryan) for the study. Interviews and a drawing activity were used with the 9 informants to collect the data that served as the basis for analysis.

\section{Interviews}

The interviews were semi-structured and open-ended, beginning with broad questions (e.g., "What makes a good day for you?”) and narrowing in on the experiences that illuminate the phenomenon of interest-intrinsic motivation and information seeking (Creswell, 1998, p. 121). The informant and researcher collaborated together to construct meaning from the student's experiences. The information sought in these interviews was: a) the factors in the students' life experiences that have contributed to their dispositions toward seeking information generally, and b) the factors surrounding their information seeking experiences, especially the types of questions they ask. The protocol for the second line of questioning (information seeking experiences) was developed by Shenton and Dixon (2003) for a study of the information seeking behavior and needs of young people, and was based on a similar study by Dervin et al. (1976).

The researcher assumed a role somewhere between a friend and a leader, and maintained flexibility based on the reactions and contributions of the informants. Since the informants were children, special consideration was given to the issues of ability, power, and ethics when working with this population.

\section{Drawing Activities}

Based on a procedure established by Amabile (1982), students were given paper and a variety of drawing instruments and were asked to illustrate two topics. The two topics were: "what makes a good day for me," and "a time when I sought information." The researcher's observations of the drawings were not based on specialized art skills, but on the perspective as a researcher of the students' lived experiences. In addition, the input and interpretations of certified elementary art teachers provided a means of analysis and reliability checking. Drawing exercises were conducted at the selected school sites.

\section{Main Findings}

Analysis of the data indicates that students came from various family situations and socio-economic backgrounds, exhibited different communication styles, and described varied school experiences. They exhibited an affinity for play, a tendency toward creativity, and the disposition of non-competitiveness. Culture was found to influence students' psychological need fulfilment. With regard to their information seeking behavior, informants indicated a variety of information seeking styles and interests, engaged in information seeking in order to 
facilitate maturation into their next developmental stage (adolescence), and recounted diverse and successful information seeking episodes.

A point of passion experience occurred in the lives of all of the informants (most at the age of four), and the presence of "anchor" relationships helped in fostering their intrinsic motivation for information seeking. Students specified that interest/relevance of topic, working in a group, at least some choice in the task, creating a final product, and fewer time constraints are all components of intrinsically motivating information seeking episodes.

\section{Discussion and Conclusions}

While it is important to keep in mind that the observations drawn from this exercise are applicable only to the study's pool of informants, the following conclusions may shed light on issues surrounding the general topic of intrinsic motivation within the framework of information seeking.

\section{Diversity}

Students in the study who were identified as intrinsically motivated to seek information came from many family situations and backgrounds. The typical assumption is that these children fit an "advantaged" profile-white, rich, high achievers with doting parents who provide them with every asset needed for success. However, the fact is that while some of the children in the study tended toward the "advantaged" profile, most did not.

Anchor relationships. Informants' family configurations and situations varied (though most were living with both their mother and father), but all described "anchor" relationships, people who supported their interests and information seeking behavior. The conclusion is that these "anchor" relationships foster intrinsic motivation for information seeking, and that though these relationships are usually adult relatives, they need not be. Others can and have stepped into the "anchor" relationship role.

Cultural influences. The data suggest that the minority student's cultural and ethnic background influenced which need fulfillment contributed most to fostering his intrinsic motivation for information seeking. The tension lies between the need for autonomy, which appears to be salient for people from individualistic cultures, and relatedness, which seems to be the most prominent need for people from collectivist countries (Chirkov \& Ryanan, 2001; Deci, Ryan, Gagne, Leone, Usunov, \& Kornazheva, 2001, Hayamizu, 1997; Yamauchi \& Tanaka, 1998). The conclusion is that allowing for student choice with regard to working with others or working individually fosters intrinsic motivation for information seeking for more students, regardless of their ethnic and cultural backgrounds.

Success in school. Although all of the children perceived themselves as competent in at least one area, these were not necessarily competencies that would help them succeed in school. Couple this with the varying communication styles of the students, and it leads to the conclusion that educators may not easily recognize children who are intrinsically motivated for information seeking in their classrooms and libraries. While it is common in some schools to reduce, limit, or eliminate information seeking experiences such as research projects and even library sessions in order to provide time for students to receive special services (e.g., remedial reading, help for learning disabilities, and gifted instruction), as well as to neglect 
those who do not seem competent or do not communicate their information needs well, these "special" students can and do benefit from school-related information seeking experiences, as do students who fit the "normal" profile. The indication is that research and library-related experiences contribute to intrinsic motivation for information seeking for many types of students, both within and outside of what might be considered the "norm."

\section{Similarity}

Students in the study who were identified as intrinsically motivated for information seeking exhibited an affinity for play, a tendency toward creativity, and the disposition of non-competiveness.

Affinity for play. The play experiences the informants described were indicated to contribute to the fulfillment of students' needs for competence, autonomy, and relatedness, all principles espoused by SDT (Deci \& Ryan, 1985) to foster intrinsic motivation. While it may or may not be true that most students-intrinsically motivated for information seeking or not - enjoy and thrive on play, based on my experiences working with children the students in the study seemed to have a particular affinity for it. In fact, not only did they discuss play often and enthusiastically, students also connected play with information seeking. Informants described incidents of play that involved information seeking, and information seeking was indicated as play for many of the students. It is my conclusion that the play life of children is an important contributor to their intrinsic motivation for information seeking. However, further study is required to determine if the affinity for play is more poignant for students who are intrinsically motivated for information seeking than it is for other children.

Creativity. Students in the study exhibited a tendency toward creativity, which was indicated by statements in their interviews as well as by the evaluations of the art teachers. They described creativity as an outlet in itself, a way to express interest, and as an object for information seeking. The data suggest that creativity both contributed to and manifested itself in intrinsic motivation for information seeking in the lives of the informants. The assumption is that students who engage in information seeking experiences that include the use of creativity are more likely to be intrinsically motivated for both the information seeking and the creative aspects of the activity, and that the inclusion of each enhances the intrinsically motivating aspects of the other.

Non-competitiveness. Informants in the current study exhibited a disposition of non-competitiveness. They rarely mentioned winning, losing, or competition in any domain. The reasons they gave for engaging in competitive activities was for the joy of participation and because they were competent or were striving for competence-both intrinsic reasons. I conclude from the data that the effect of the extrinsic motivator, competition, to diminish intrinsic motivation is decreased through a focus on the intrinsic reasons for participation in an activity as well as on the functional feedback of personal performance. Since research indicates that extrinsic motivators decrease intrinsic motivation (Deci, Betley, Kahle, Abrams, \& Porac, 1981), it would be logical to conclude that students who focus on participating in competitive activities for intrinsic reasons are less likely to be affected negatively with regard to intrinsic motivation, particularly in the domain of information seeking, as is the case in the current study. 


\section{Information Seeking Behavior}

The informants indicated having a variety of information seeking styles and interests, and recounted diverse and successful information seeking episodes.

Information seeking styles. All of the students recounted experiences using computer technology for information seeking. However, considerably fewer students gravitated to computer technology as their primary information seeking medium (1), compared with those who did so for books (4). This finding might be considered surprising in this day and age of increasingly abundant technology. Notwithstanding, studies have shown that children are not as successful nor as motivated by computer use as the conventional wisdom would suggest when one considers the popularity of computer games in contemporary society and assumptions drawn about youth and technology (Bilal, 1999; Bilal, 2000; Bilal \& Kirby, 2002; Spavold, 1990). At the same time, one must remember that this group of children was identified as intrinsically motivated for information seeking and as such may not represent patterns from the general population. The data did not indicate that they were unsuccessful nor that they disliked using the computer; it simply indicated that they had chosen other media as their primary information seeking sources, media for which they had more access, or presumably with which they felt more comfortable.

The styles they did choose more often-using books and observing — could indicate inclination toward their own particular learning styles (Gardner, 1999). It is also important to consider that 2 students could not be "pinned down" to specific information seeking styles because they tended to focus on their interests and sought information regarding those interests using any medium they could find. In fact, all of the students indicated using at least two media types for information seeking, and 8 of the students indicated using at least three.

The students use of their primary information seeking sources, and their versatility in using secondary sources would lead one to conclude that students who are intrinsically motivated to seek information a) begin with the media for which they have more access, for which they are best suited, and/or with which they are most comfortable; b) then they develop more questions from that experience; and then c) expand the focus to other sources as the need or desire for more information arises. It would be logical to conclude that students who are exposed to various media types and who are allowed/encouraged to use them at will would be more successful as well as more intrinsically motivated to seek information.

The point of passion experience. All of the students in the study described a point of passion experience, a particular event they remember that ignited an interest they have since pursued. Most of the students (6 of 9) described having this experience at the age of four or five. In the same vein, a majority of the students also indicated support from others, generally an adult relative, for pursing the interest. While the research on the long-lasting effects of interests cultivated in childhood is inconclusive (Hidi \& McLaren, 1990), anecdotal evidence points to the possibility that point of passion experiences fostered by others may last until adulthood and, in fact, may affect a child's decisions for life (B. Birney, personal communication, October 26, 2008; Fulton, 1993). Combine this with the universal presence of the "anchor" relationship (who may or may not have been the person who supported them after the point of passion experience) in the lives of the informants, and the data point to the importance of an influential person(s) who fosters intrinsic motivation for information seeking in the life of each child. 
Developmental basis for information seeking. Students in the study shared their many different interests during the interviews and depicted them in their drawings. During the analysis of the data, I sorted these interests into a typology, then classified them into an adapted model based on ATheoretical Model of Urban Teen Development (Agosto \& Hughes-Hassell, 2006a, 2006b). Instead of using Havighurst's Developmental Tasks of Adolecence (1972), I used Havighurst's Developmental Tasks of Middle Childhood (1972) as the basis of the model. Based on the interests indicated by the children, a variable, the creative self, was added to the model (the same variable added by Agosto and HughesHassell as indicated by the data they gathered from the teens in their study). The conclusion from this process is that upper elementary students who are intrinsically motivated to seek information facilitate maturation into their next developmental stage, adolescence, through their information seeking behavior. It could be presumed that upper elementary students outside of the profile of the informants in the study also seek information for the same developmental reasons, but more study is required to confirm this conclusion.

The task definition of "favorite" information seeking episodes. Students were asked about their "favorite" information seeking episodes. These were recorded and stratified into an adapted Taxonomy of Tasks (Bilal, 2002). The Taxonomy of Tasks provides a framework into which the researcher can classify tasks into three categories: task type, task nature, and task administration. I added a fourth category, task relationship, based on the information gathered from the students. While the three task patterns representing students' "favorite" information seeking episodes included both open and closed task types, simple and complex task natures, semi-assigned and fully self-generated task administration, and both group and individual task relationships, the salient feature of the episodes was that none of them included tasks that were fully assigned. Since the "favorites" were the most intrinsically motivating episodes of students identified as intrinsically motivated for information seeking, the assumption is that fully assigned tasks are least likely to be intrinsically motivating to students. Similarly, when students were asked why they chose their "favorite" episodes, one of their responses was choice of aspect in information seeking. This element in the information seeking episodes aligns with the SDT (Deci \& Ryan, 1985) principle that autonomy is an essential component for intrinsic motivation.

Other reasons students gave for choosing their "favorite" information seeking episodes also coincide with SDT principles. They are (given in order of frequency): relevance of/interest in topic (interest as the basis of intrinsic motivation), working in a group (relatedness), the experience of information seeking itself (indication of intrinsic motivation for information seeking), creating the final product (creativity), and no time limit (extrinsic motivators decrease intrinsic motivation). I conclude that students who participate in information seeking tasks that incorporate principles of intrinsic motivation (e.g., as outlined by SDT) in their design, are more likely to be intrinsically motivated by those experiences, and are more likely to engage in information seeking on their own.

\section{Implications and Recommendations}

Implications and recommendations for practitioners include use of playful and creative teaching strategies, engagement of constructivist pedagogy, providing a broad variety of material formats (especially realia) for children, conducting research activities with younger children, arranging for adult mentors for children based on common interests, and educating parents in the role of fostering their children's natural interests. 
By using strategies and techniques that stimulate and build on the innate interests of students, library media specialists move beyond "teaching to the test." Instead, they become educators taking an active role in fostering in their young patrons a disposition for learning that may last a lifetime. 


\section{References}

Agosto, D. E., \& Hughes-Hassell, S. (2006a). Toward a model of the everydaylife information needs of urban teenagers, part 1: Theoretical model. Journal of the American Society for Information Science and Technology, 57(10), 1394-1403.

Agosto, D. E., \& Hughes-Hassell, S. (2006b). Toward a model of the everydaylife information needs of urban teenagers, part 2: Theoretical model. Journal of the American Society for Information Science and Technology, 57(11), 1418-1426.

Amabile, T. M. (1982). Social psychology of creativity: A consensual assessment technique. Journal of Personality and Social Psychology, 43(5), 997-1013.

Aversa, E. S. (1985). Teaching online searching: A review of recent research and some recommendations for school media specialists. School Library Media Quarterly, 13(3-4), 215-219.

Barlow, D., Karnes, K., \& Marchionini, G. (1987). CD-ROM in a high school library media center: A research project. School Library Journal, 34, 66-68.

Berlyne, D. E. (1960). Conflict, arousal and curiosity. New York: McGraw-Hill.

Bilal, D. (1999). Web search engines for children: A comparative study and performance evaluation of Yahooligans!, Ask Jeeves for Kids' ${ }^{\mathrm{TM}}$, and Super Snooper ${ }^{\mathrm{TM}}$. ASIS '99: Proceedings of the $62^{\text {nd }}$ American Society for Information Science (ASIS) Annual Meeting, Vol. 36. Knowledge: Creation, Organization and Use (pp. 70-83). Medford, NJ: Information Today, Inc.

Bilal, D. (2000). Children's use of the Yahooligans! Web search engine I: Cognitive, physical, and affective behaviors on fact-based search tasks. Journal of the American Society for Information Science and Technology, 51, 646-665.

Bilal, D. (2001). Children's use of the Yahooligans! Web search engine. II. Cognitive and physical behaviors on research search tasks. Journal of the American Society for Information Science and Technology, 52, 118-137.

Bilal, D. (2002). Children's use of the Yahooligans! Web search engine. III. Cognitive and physical behaviors on fully self-generated search tasks. Journal of the American Society for Information Science and Technology, 53(13), 1170-1183.

Bilal, D. (2003). Draw and tell: Children as designers of Web interfaces. In R. Todd (Ed.), Humanizing information technology: From ideas to bits and back. Proceedings of the 66th ASIST Annual Meeting. Vol 40 (135-142). Medford, NJ: Information Today.

Bilal, D., \& Kirby, J. (2002). Differences and similarities in information seeking: Children and adults as Web users. Information Processing and Management, 38, 649-670.

Borgman, C. L., Chignell, M. C., \& Valdez, F. (1989). Designing an information retrieval interface based on children's categorization of knowledge: A pilot study. In J. Katzer and G. Newby (Eds.), Proceedings of the American Society for Information Science annual meeting. Washington, D. C., October 29Novermber 2.

Borgman, C. L., Hirsh, S. G., Walter, V. A., \& Gallagher, A. L. (1995). Children's searching behavior on browsing and keyword online catalogs: The science library catalog project. Journal of the American Society for Information Science, 46(9), 663-684.

Borgman, C. L., Krieger, D., Gallagher, A. L., and Bower, J. (1990). Children’s use science library: Exploratory research. School Library Media Quarterly, 18(2), 108-111. 
Broch, E. (2000). Children's search engines from an information search process perpective. School Library Media Research, 3, 1-18. Retrieved July 18, 2005 from http://www.ala.org/ala/aasl/aaslpubsandjournals/slmrb/slmrcontents/volume32000/childrens.htm

Burdick, T. A. (1996). Success and diversity in information seeking: Gender and the information search styles model. School Library Media Quarterly, 25, 19-26.

Callison, D., Daniels, A., Estell, D. \& Gunderson, H. (1986). Using Wilsearch with high school students: A pilot study. East Lansing, MI: National Center for Research on Teacher Learning. (ERIC Document Reproduction Service No. 275 343).

Chirkov, V. I., \& Ryan, R. M. (2001). Parent and teacher autonomy support in Russian and U. S. adolescents. Journal of Cross-Cultural Psychology, 32, 618-635.

Clyde, L. A., \& Kirk, J. (1989). The use of electronic information systems in Australian schools: A preliminary survey. School Library Media Quarterly, 17(4), 193-199.

Craver, K. W. (1985). Teaching online bibliographic searching to high school students. Top of the News, 41(2), $131-136$

Creswell, J. W. (1998). Qualitative inquiry and research design: Choosing among five traditions. Thousand Oaks, CA: Sage.

Csikszentmihalyi, M. (1975). Beyond boredom and anxiety. San Francisco: Jossey-Bass, 1975.

Csikszentmihalyi, M. (1990). Flow: The psychology of optimal experience. New York: Haper \& Row.

Deci, E.L., Betley, G., Kahle, J., Abrams, L., \& Porac, J. ( 1981). When trying to win: Competition and intrinsic motivation. Personality and Social Psychology Bulletin, 7, 79-83.

Deci, E. L., \& Ryan, R. M. (1985). Intrinsic motivation and self-determination in human behavior. New York: Plenum Press.

Deci, E. L., Ryan, R. M., Gagné, M., Leone, D. R., Usunov., J., \& Kornazheva, B. P. (2001). Need satisfaction, motivation, and well-being in the work organizations of a former Eastern Bloc country. Personality and Social Psychology Bulletin, 27, 930-942.

Dervin, B., et al. (1976). The development of strategies for dealing with the information needs of urban residents, phase I-The citizen study. Washington: School of Communications, University of Washington.

Edmonton Public Schools. (1983). Utilization of a micro computer in an elementary school learning resource center. East Lansing, MI: National Center for Research on Teacher Learning. (ERIC Document Reproduction Service No. 239 601).

Everhart, N. (2005). A crosscultural inquiry into the levels of implementation of Accelerated Reader and its effect on motivation and extent of reading: Perspectives from Schotland and England. School Library Media Research, 8, 1-15. Retrieved April 19, 2006 from http://www.ala.org/ala/aasl/aaslpubsandjournals/slmrb/slmrcontents/volume82005/reader.htm

Farmer, L. S. (2007). What is the question? IFLA Journal, 33(1), 41-49.

Freud, S. (1914). On narcissism. In The standard edition of the complete works of Sigmund Freud (Vol. 14). London: Hogarth Press, 1957 (Originally published, 1914).

Freud, S. (1915). Instincts and their vicissitudes. In Collected Papers (Vol. 4), London: Hogarth, 1925 (Originally published, 1915). 
Fulton, R. (Director). (1993). Eric Carle: Picture writer [video tape]. New York: Philomel Books and Scholastic, Inc.

Gardner, H. (1999). Intelligence reframed: Multiple intelligences for the $21^{\text {st }}$ century. New York: Basic Books.

Gross, M. (1995). Imposed query. RQ, 35(1), 236-243.

Harter, S. (1980). A scale of intrinsic versus extrinsic orientation in the classroom (Available from Susan Harter, Department of Psychology, University of Denver, Denver, CO 80208).

Harter, S. (1981). A new self-report scale of intrinsic versus extrinsic orientation in the classroom: Motivational and informational components. Developmental Psychology, 17 (3), 300-312.

Havighurst, R. J. (1972). Developmental tasks and education ( $3^{\text {rd }}$ ed.). New York: Longman.

Hayamizu, T. (1997). Between intrinsic and extrinsic motivation: Examination of reasons for academic study based on the theory of internalization. Japanese Psychological Research, 39, 98-108.

Hidi, S., \& Baird, W. (1986). Interestingness-A neglected variable in discourse processing. Cognitive Science, 10, 179-194.

Hidi, S., \& McLaren, J. (1990). The effect of topic and theme interestingness on the production of school expositions. In H. Mandel, E. de Corte, N. Bennett, \& H. F. Fredrich (Eds.), Learning and instruction (Vol. 2.2, pp. 295-308). Oxford,:Pergamon.

Hirsh, S. (1999). Children's relevance criteria and information seeking on electronic resources. Journal of the American Society for Information Science, 50(14), 1265-1283.

Hull, C. L. (1943). Principles of behavior: An introduction to behavior theory. New York: Appleton-CenturyCrofts.

Koch, S. (1956). Behavior as "intrinsically” regulated: Work notes toward a pre-theory of phenomena called “motivational.” In M. R. Jones (Ed.), Nebraska symposium on motivation (Vol. 4). Lincoln: University of Nebraska Press.

Koch, S. (1961). Psychological science vs. the science-humanism antinomy: Intimations of a significant science of man. American Psychologist, 16, 629-639.

Krapp, A., \& Fink, B. (1992). The development and function of interests during the critical transition from home to preschool. In K. A. Renninger, Hidi, S., \& Krapp, A. (Eds.), The role of interest in learning and development (pp. 397-429). Hillsdale, NY: Lawrence Earlbaum.

Krashen, S. D. (2003). The (lack of) experimental evidence supporting the use of Accelerated Reader. Journal of Children's Literature, 29(2), 9-30.

Kuhlthau, C. C. (2004). Seeking meaning: A process approach to library and information services (2 ${ }^{\text {nd }}$ ed.). Westport, CT: Libraries Unlimited.

Kuhlthau, C. C., \& Sherman, J. C. (1990). On-line computer databases in school library media centers. In C. Wargner (Ed.) Technology in today’s schools (pp. 51-56). Alexandria, VA: Association for Supervision and Curriculum Development.

Large, A., Beheshti, J., \& Rahman, R. (2002). Design criteria for children's Web portals: The users speak out. Journal of the American Society for Information Science andTechnology, 53, 79-94.

Lepper, M. R., Corpus, J. H., \& Iyengar, S. S. (2005). Intrinsic and extrinsic motivational orientations in the classroom: Age differences and academic correlates. Journal of Educational Psychology, 97 (2), 184196. 
Liebscher, P. , \& Marchionini, G. (1988). Browse and analytical search strategies in a full text CD-ROM encyclopedia. School Library Media Quarterly, 16(4), 223-233.

McLoyd, V. (1979). The effects of extrinsic rewards of differential value on high and low intrinsic interest. Child Development, 50, 1010-1019.

Mancall, J. \& Dresking, D. (1984). Teaching online bibliographic skills to high school students. East Lansing, MI: National Center for Research on Teacher Learning. (ERIC Document Reproduction Service No. 252 823).

Marchionini, G. \& Teague, J. (1987). Elementary students' use of electronic information services: An exploratory study. Journal of Research on Computing in Education, 20(2), 139-144.

Montgomery, P. (1987). Library media literacy: Making the library media and reading connection. School Library Media Quarterly, 16(1), 32-35.

Murray, H. A. (1938). Explorations in personality. New York: Oxford University Press.

No Child Left Behind Act of 2001, Pub. L. No. 107-110 (2002).

Oliver, R., \& Oliver, H. (1997). Using context to promote learning from information-seeking tasks. (1997). Journal of the American Society for Information Science, 48(6), 519-526.

Poston-Anderson, B., \& Edwards, S. (1993). The role of information in helping adolescent girls with their life concerns. School Library Media Quarterly, 22(1), 1-6.

Robbins, E. \& Thompson, L. (1991). A study of the Indianapolis-Marion County public library's summer reading program for children. East Lansing, MI: National Center for Research on Teacher Learning. (ERIC Document Reproduction Service No. ED355647).

Ryan, R. M. \& Deci, E. L. (2000). Self-determination theory and the facilitation of intrinsic motivation, social development, and well-being. American Psychologist, 55 (1), 68-78.

Schacter, J., Chung, G. K., \& Dorr, A. (1998). Children’s internet searching on complex problems: Performance and process analyses. Journal of the American Society for Information Science, 49(9), 840-849.

Sheldon, K. M., \& Biddle, B. J. (1998). Standards, accountability, and school reform: Perils and pitfalls. Teachers College Record, 100(1), 164-80.

Shenton, A. K. (2004). Young people's use of paper serials: The results of a recent research project in England. The Serials Librarian, 47(3), 45-56.

Shenton, A. K., \& Dixon, P. (2003). Models of young people’s information seeking. Journal of Librarianship and Information Science, 35(5), 5-22.

Small, R. V. (1998). Designing motivation into library and information skills instruction. School Library Media Quarterly Online, 1, 1-11. Retrieved July 19, 2005 from http://www.ala.org/ala/aasl/aaslpubsandjournals/slmrb/slmrcontents/volume11998slmqo/small.htm

Small, R. V. (1999). An exploration of motivational strategies used by library media specialists during library and information skills instruction. School Library Media Research, 2, 1-23. Retrieved July 18, 2005 from http://www.ala.org/ala/aasl/aaslpubsandjournals/slmrb/slmrcontents/volume21999/vol2small.htm

Solomon, P. (1993). Children's information retrieval behavior: A case analysis of an OPAC. Journal of the American Society for Information Science, 44(5), 245-264.

Spavold, J. (1990). The child as naïve user: A study of database use with young children. International Journal of Man-Machine Studies, 32, 603-625. 
Taylor, R. S. (1968). Question-negotiation and information seeking in libraries. College and Research Libraries, 29, 178-194.

Tenopir, C. (1986). Online searching in schools. Library Journal, 111(2), 60-61.

Todd, R.J. (1999a). Utilization of heroin information by adolescent girls in Australia: A

cognitive analysis. Journal of the American Society for Information Science, 50(1),10-23.

Todd, R.J. (1999b). Back to our beginnings: Information utilization, Bertram Brookes and the Fundamental Equation of Information Science. Information Processing and Management, 35, 851-870.

Vroom, V. H. (1964). Work and motivation. New York: Wiley.

Ward-Callaghan, L. (1987). The effect of emerging technologies on children's library service. Library Trends. 35(3), 427-447.

Wozney, L. A. (1982). Online bibliographic searching and student use of information: An innovative teaching approach. School Library Media Quarterly, 11(1), 53-42.

White, R. W. (1959). Motivation reconsidered: The concept of competence. Psychological Review, 66(5), 297323.

\section{Biographical Notes}

Sherry R. Crow is the Assistant Professor of School Library Science/Educational Media at the College of Education of the University of Nebraska Kearney. Her research interest is children's intrinsic motivation, particularly in the area of information seeking.

\section{Statement of Originality}

This statement certifies that the paper above is based upon original research undertaken by the author and that the paper was conceived and written by the author(s) alone and has not been published elsewhere (except for excerpts taken from the author's dissertation, which has been submitted by Emporia State University to ProQuest). All information and ideas from others is referenced. 